\title{
The effect of soil on the biodegradable behavior of green composites under various environmental (ambient) temperatures
}

\author{
H. Katogi \& K. Takemura \\ Department of Mechanical Engineering, Kanagawa University, Japan
}

\begin{abstract}
In this study, the biodegradable behavior of green composites under different $\mathrm{pH}$ (concentration of hydrogen ion) soil and environmental temperature was investigated. The biodegradation test was conducted in 90 days. The environmental temperatures were room temperature (RT) and $50^{\circ} \mathrm{C}$. The acid soil ( $\mathrm{pH} 4.2)$, neutral soil $(\mathrm{pH} 5.5)$ and alkali soil $(\mathrm{pH}$ 7.4) were used as environmental soil. A quasi-static tensile test was conducted after the biodegradation test. As a result, the mass rate of green composites in all soils at RT almost did not change by 60 days. After that, their mass rates decreased. The mass rates of green composites in all soils at $50^{\circ} \mathrm{C}$ moderately decreased with an increase of biodegradation time by 60 days. After that, their mass rates rapidly decreased. In the case of all soils at RT and $50^{\circ} \mathrm{C}$, the tensile strength and Young's modulus of green composites decreased with an increase of biodegradation time by 60 days. After that, they did not change any more. The tensile strength of the composites in all soils at $50^{\circ} \mathrm{C}$ decreased with an increase of biodegradation time by 60 days. After that, they moderately decreased except for acid soil. Young's modulus of composites in all soils for 30 days at $50^{\circ} \mathrm{C}$ rapidly decreased. After that, their Young's modulus moderately decreased. Their results implied that the tensile property of green composites decreased due to the biodegradation of PLA resin in soils at environmental temperatures.

Keywords: green composites, PLA, biodegradable behavior, tensile property, environmental temperature, $\mathrm{pH}$ soil.
\end{abstract}




\section{Introduction}

Green composite material, which is composed of biodegradable resin and natural fiber, has been expected as an alternative material to glass fiber reinforced plastics. Polylactic acid (PLA) resin is used as a matrix of the green composites. The life cycle assessment of PLA resin is lower than that of petroleum resin [1]. So, green composites using PLA resin will be used for wider application.

There are some reports about the molding condition [2-4] and mechanical properties [5-9] of green composites. And the design and fabrication of a micro EV (Electric Vehicle) made of green composites have been studied [10]. But, biodegradable behavior of green composites should be investigated for waste disposal after use. Ochi and Takagi [11] reported about the biodegradable behavior of unidirectional fiber reinforced green composites under compost. The tensile strength of green composites decreased $80 \%$ after 20 days composting. Maiti et al. [12] reported about the study of compostable behavior of jute nano fiber reinforced composites in aerobic compost environment. Mass loss of composites decreased $18 \%$ after biodegradation time for 50 days. Lunt [13] reported about the biodegradable behavior of PLA resin. PLA resin rapidly degraded due to decrease of molecular weight of PLA in soil under environmental temperature. But, there are few reports about effect of soil on biodegradable behavior of green composites under environmental temperature.

In this study, effects of acid, neutral and alkaline soils on the biodegradation behavior of green composites under environmental temperature were investigated.

\section{Specimen and testing method}

\subsection{Constituent materials and molding condition}

PLA sheet (TERAMAK SS300, Unitika Co., Ltd.) was used as matrix. Plain woven jute fiber (Tomato Co., Ltd.) was used as reinforcement. The molding temperature was $190^{\circ} \mathrm{C}$, molding pressure was $1 \mathrm{MPa}$, and holding time was 20 min. Then, the mold was cooled down to room temperature (RT) using city running water. The fiber weight fraction of composites was $40 \mathrm{wt} \%$.

\subsection{Biodegradation test}

As a condition of biodegradation test, acid soil (AC) ( $\mathrm{pH} 4.2)$, neutral soil (NS) $(\mathrm{pH} 5.5)$ and alkali soil (AS) ( $\mathrm{pH}$ 7.4) were used. Environmental temperatures were RT and $50^{\circ} \mathrm{C}$. Biodegradation test (Figure 1) was conducted in 90 days. The specimen size was $250 \mathrm{~mm}$ long, $15 \mathrm{~mm}$ wide and $3 \mathrm{~mm}$ thick.

The mass rate $M_{\mathrm{c}}$ of composites after biodegradation test was calculated by following equation (1).

$$
M_{c}=\frac{M_{1}}{M_{o}}
$$

where, $M_{0}$ is the mass of composites before the biodegradation test and $M_{1}$ is the mass of composites after the biodegradation test. 


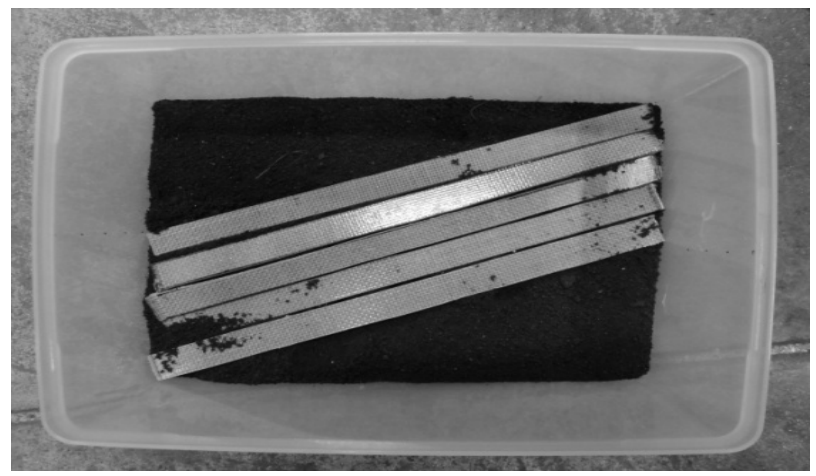

Figure 1: Biodegradation test.

\subsection{Quasi-static tensile test}

A quasi-static tensile test was conducted based on Japanese Industrial Standard (JIS) K 7164. The crosshead speed was $1 \mathrm{~mm} / \mathrm{min}$. Environmental temperature was RT. The number of specimens was three.

\subsection{Surface observation after biodegradation test}

For investigation of biodegradation behavior, the surfaces of composites were observed by using Scanning Electron Microscope (SEM) and optical microscope after biodegradation test.

\section{Results and discussion}

\subsection{Biodegradation behavior}

Figure 2 shows the relationship between mass rate and biodegradation time. Mass rate is defined as the mass divided by the initial mass. In the case of all soils at RT, the mass rate of composites did not change by 60 days. After that, their mass rates decreased. In the case of $\mathrm{AC}$ and $\mathrm{AL}$ at $50^{\circ} \mathrm{C}$, mass rates of composites moderately decreased with an increase of biodegradation time by 60 days. But, the mass rate of composites in NS almost did not change. After that, their mass rates in all soils rapidly decreased. And, the mass rates of composites in $\mathrm{AC}$ and $\mathrm{AL}$ at biodegradation time for 90 days was lower than that of composites in NS. These results implied that biodegradation of PLA resin occurred due to threadlike bacterium and actinomyces [14] in soil at environmental temperature. 


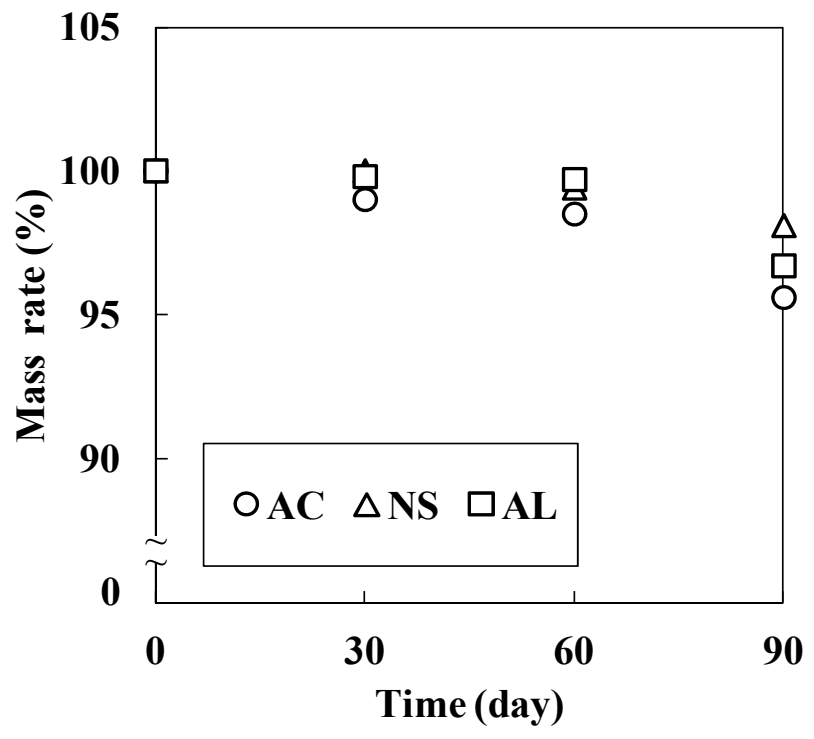

(a) RT.

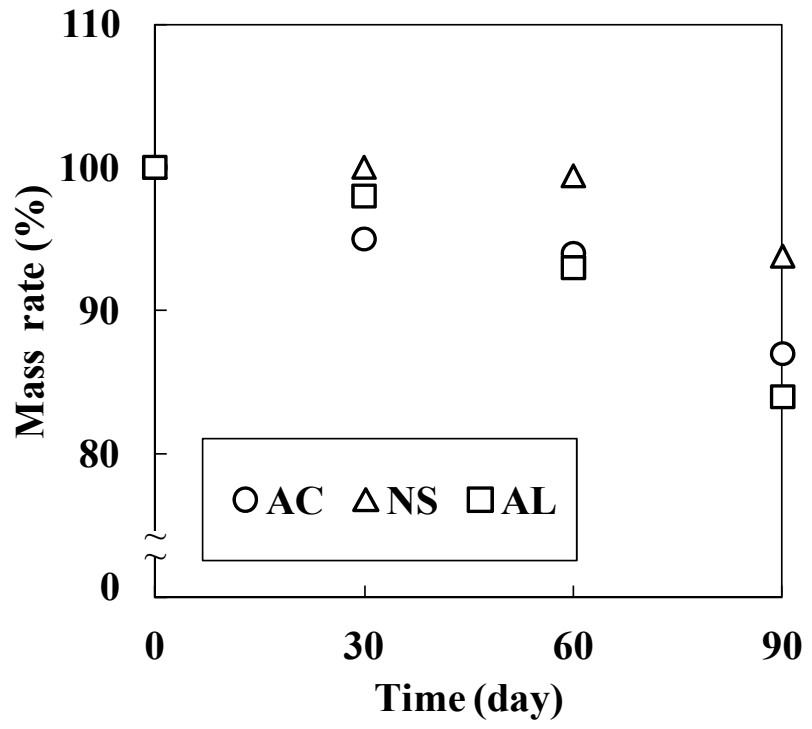

(b) $50^{\circ} \mathrm{C}$.

Figure 2: Relationship between mass rate and biodegradation time.

\subsection{Tensile property of composites after biodegradation test}

Figure 3 shows the tensile property of composites after biodegradation test. Tensile strength and Young's modulus of green composites in all soils at RT 


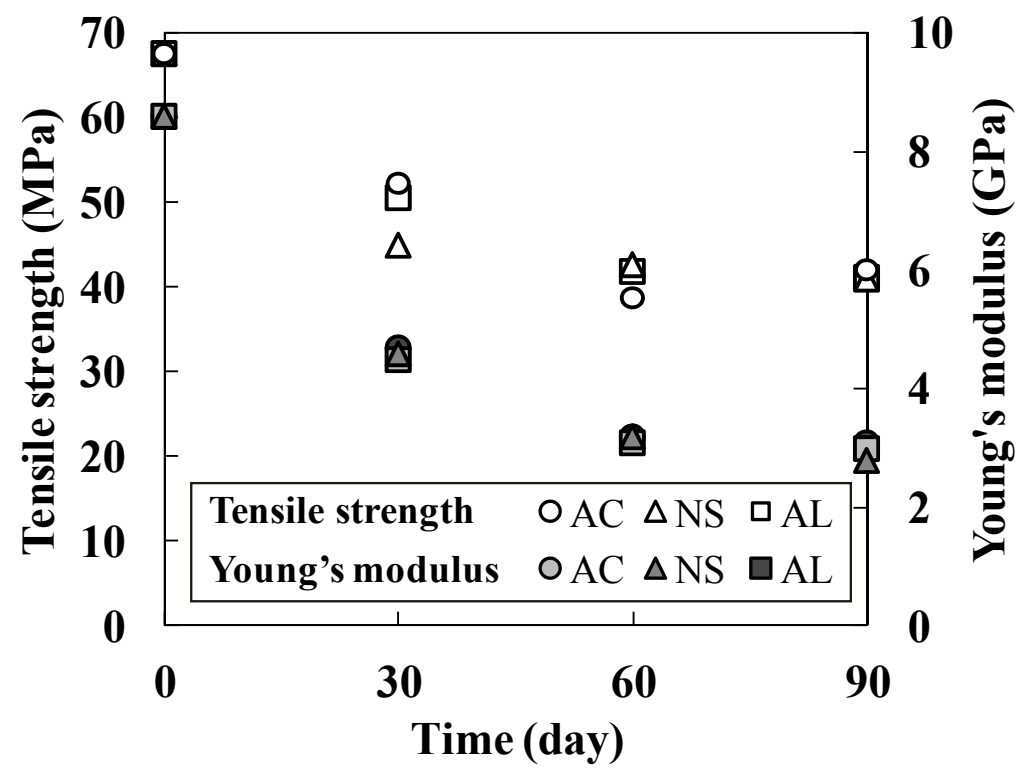

(a) RT.

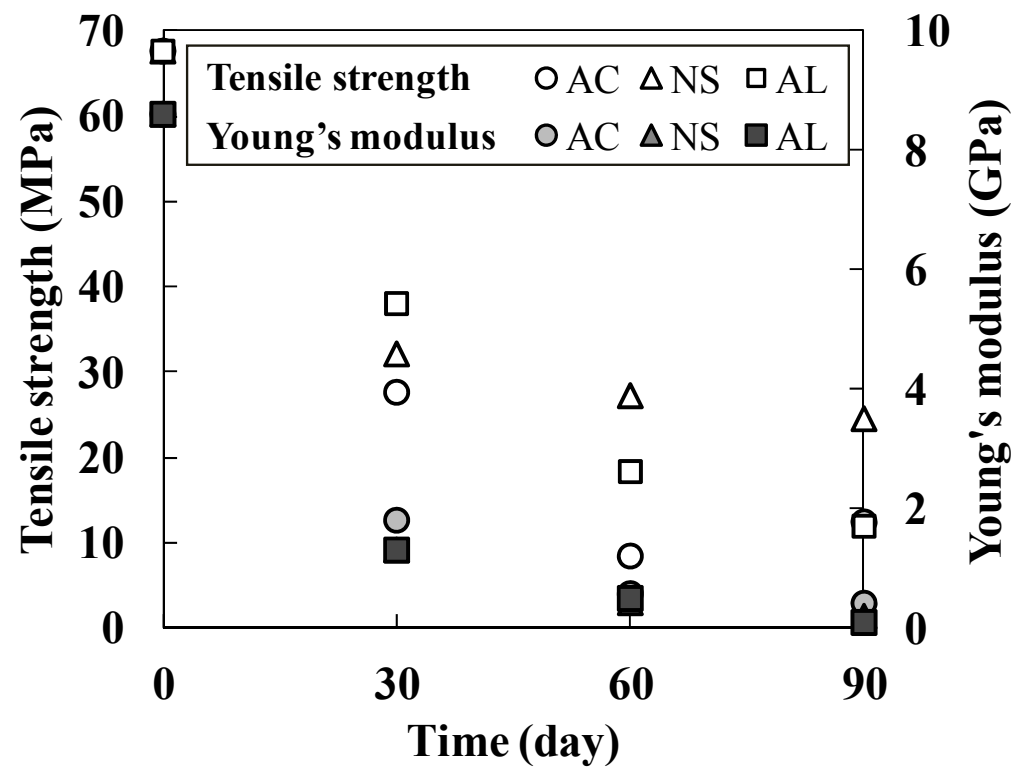

(b) $50^{\circ} \mathrm{C}$.

Figure 3: Tensile property of composites after biodegradation test. 
decreased with an increase of biodegradation time by 60 days. After that, they did not change any more. Tensile strength of composites in all soils at $50^{\circ} \mathrm{C}$ decreased with an increase of biodegradation time by 60 days. After that, tensile strength of composites in NS and AL moderately decreased. In case of biodegradation time for 90 days at $50^{\circ} \mathrm{C}$, tensile strengths of composites in $\mathrm{AC}$ and AL were lower than that of composites in NS. Young's modulus of composites in all soils at $50^{\circ} \mathrm{C}$ rapidly decreased after immersion time for 30 days. After that, they moderately decreased. Therefore, tensile property of composites was affected by biodegradation of PLA resin in soils at environmental temperatures.

\subsection{Surface observation of composites after biodegradation test}

Figures 4 and 5 show surfaces of composites after biodegradation test for 90 days under RT and $50^{\circ} \mathrm{C}$. In the case of all soils at RT, a part of surface of spun yarn was found in surface of the composites. In the case of all soils at $50^{\circ} \mathrm{C}$, surface of spun yarn was found. And PLA resin as matrix was greatly degraded.

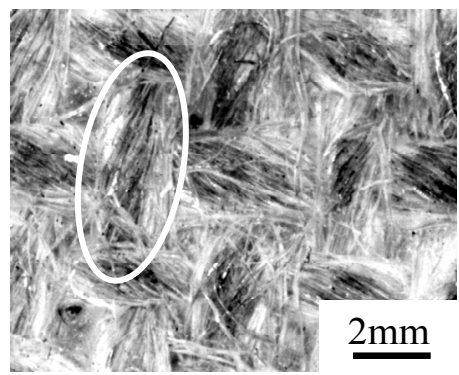

(a) AC.

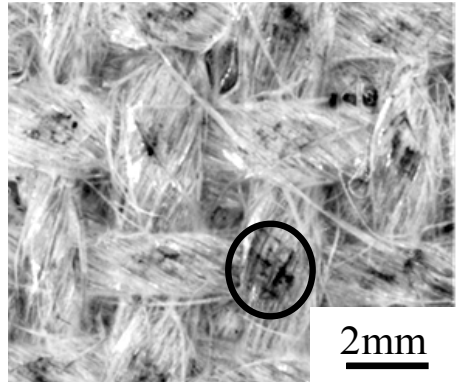

(b) NS.

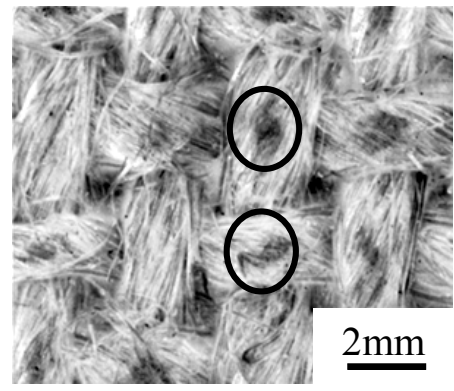

(c) AL.

Figure 4: Surfaces of composites after biodegradation test for 90 days at RT.

Jute fiber as reinforcement was probably degraded in soil at $50^{\circ} \mathrm{C}$. So, jute fiber in surface of composites was observed after biodegradation test for 90 days at $50^{\circ} \mathrm{C}$. Figure 6 shows surface observation of jute fiber in composites after a 


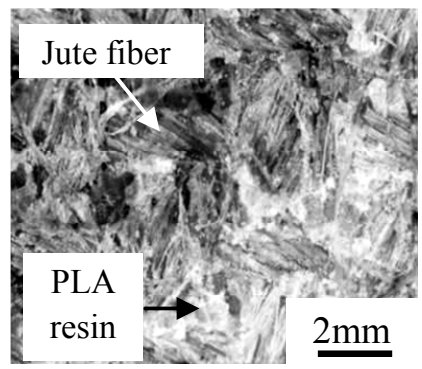

(a) AC.

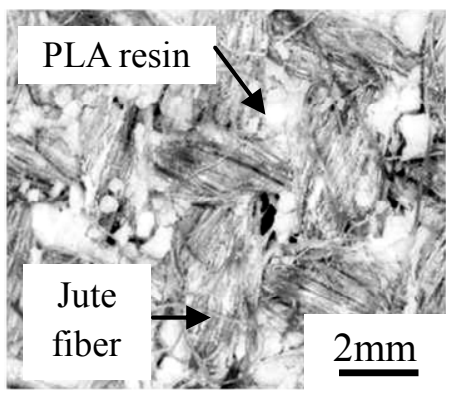

(b) NS.

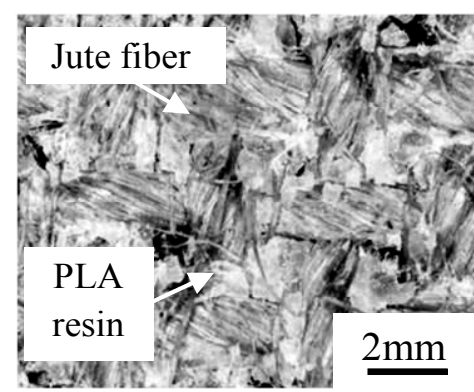

(c) AL.

Figure 5: Surfaces of composites after biodegradation test for 90 days at $50^{\circ} \mathrm{C}$.

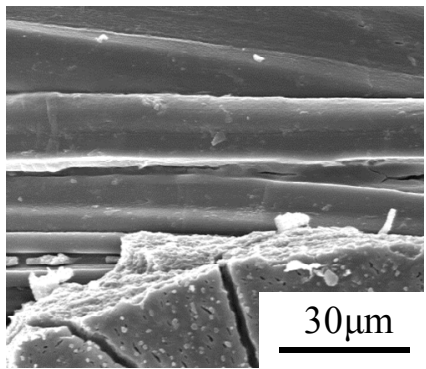

(a) AC.

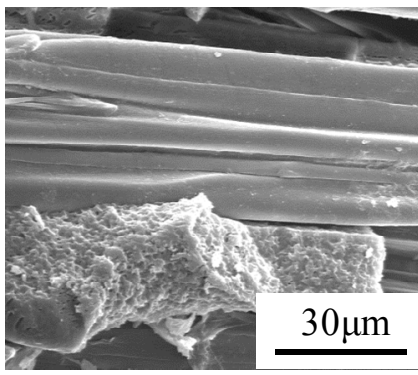

(b) NS.

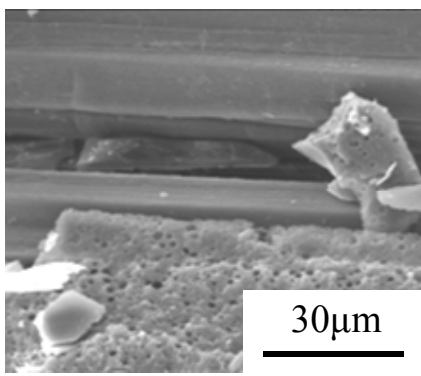

(c) AL.

Figure 6: Surface observation of jute fiber in composites after a biodegradation test for 90 days at $50^{\circ} \mathrm{C}$. 
biodegradation test for 90 days at $50^{\circ} \mathrm{C}$. Surfaces of jute fibers in all soils were smooth. And, different surfaces of jute fibers in all soils were not found. Biodegradation of PLA resin occurred from surface of composites under environmental temperature. And then PLA resin was degraded by threadlike bacterium and actinomyces [20] in soil. Therefore, mass rate and tensile property of composites were decreased by biodegradation of PLA resin.

\section{Conclusions}

In this study, the effect of soil on biodegradable behavior of composites under environmental temperature was investigated. As a result, following conclusions were obtained.

1. In the case of all soils at RT, the mass rate of composites did not change by 60 days. After that, their mass rate decreased gradually. In the case of acid soil and alkali soil at $50^{\circ} \mathrm{C}$, PLA resin as matrix was greatly degraded. And mass rate of composites decreased with an increase of biodegradation time.

2. In the case of all soils at RT, tensile properties of composites decreased with an increase of biodegradation time by 60 days. After that, they did not change any more and keep constant value. In the case of all soils at $50^{\circ} \mathrm{C}$, tensile strength of composites decreased with an increase of biodegradation time by 60 days. After that, tensile strength of composites in neutral and alkali soil moderately decreased. Young's modulus of composites in all soils for 30 days at $50^{\circ} \mathrm{C}$ rapidly decreased. After that, they moderately decreased. From the result of observation using optical microscope, it is understood that tensile property of composites decreased because biodegradation of PLA resin occurred from the surface of composites in soil under environmental temperature.

\section{References}

[1] Mochizuki, M., Murase, S. \& Matsunaga, N., Poly (lactic acid) Fiber Environmentally Friendly New Generation Fiber Made from Plant -, Sen'I gakkaishi, 62, pp. 323-329, 2006 (in Japanese).

[2] Ben, G., Kihara, Y., Nakamori, K. \& Aoki, Y., Examination of Heat Resistant Tensile Properties and Molding Conditions of Green Composites Composed of Kenaf Fibers and PLA Resin, Advanced Composite Materials, 16, pp. 361-376, 2007.

[3] Katayama, T., Tanaka, K., Murakami, T. \& Uno, K., Compression Moulding of Jute Fabric Reinforced Thermoplastics Composites based on PLA Non-Woven Fabric, Wit Transactions on The Built Environment, 85, pp. 159-167, 2006.

[4] Takemura, K., Molding conditions and mechanical properties of jute fiber reinforced composite, Key Engineering Materials, 452-453, pp. 261-264, 2010. 
[5] Pandey, J. K., Ahn, S.H., Lee, C.S., Mohanty, A. K. \& Misra, M., Recent advances in the application of natural fiber based composites, Macromolecular Materials and Engineering, 295, pp. 975-989, 2010.

[6] Wahit, M. U., Akos, N. I. \& Laffah, W. A., Influence of Natural Fibers on the Mechanical Properties and Biodegradation of Poly(Lactic Acid) and Poly(E-caprolactone) Composites: A Review, Polymer Composites, 33, pp. 1045-1053, 2012.

[7] Katogi, H., Shimamura, Y., Tohgo, K., Fujii, T. \& Takemura, K., Fatigue Behavior of Unidirectional Jute Spun Yarn Reinforced PLA. Advanced Composite Materials, 21, pp. 1-10, 2012.

[8] Takagi, H. \& Asano, A., Effects of Processing Conditions on Flexural Properties of Cellulose Nanofiber Reinforced "Green" Composites, Composites: Part A, 39, pp. 685-689, 2007.

[9] Nishino, T., Hirao, K., Kotera, M., Nakamae, K., \& Inagaki, H., Kenaf Reinforced Biodegradable Composite, Composite Science and Technology, 63, pp. 1281-1286, 2003.

[10] Amino, T., Ben, G., Sakata, K. \& Harabayashi, A., Design and Fabrication of Micro EV Made of Green Composite, Proc. of 7th Int. Workshop on Green Composite, pp. 23-25, 2012.

[11] Ochi, S., \& Takagi, H., Biodegradation Behavior of Unidirectional FiberReinforced "Green" Composites, Journal of the Society of Materials Science, Japan, 53, pp. 454-458, 2004 (in Japanese).

[12] Maiti, S., Ray, D., Mitra, D. \& Misra, M., Study of Compostable Behavior of Jute Nano Fiber Reinforced Biocopolyester Composites in Aerobic Compost Environment, Journal of Applied Polymer Science, 123, pp. 2952-2958, 2012.

[13] Lunt, J., Large-Scale Production, Properties and Commercial Applications of Polylactic Acid Polymers, Polymer Degradation and Stability, 59, pp. 145-152, 1998.

[14] Tokiwa, Y. \& Calabia, B. P., Biodegradability and Biodegradation of Poly (Lactide), Applied Microbiology and Biotechnology, 72, pp. 244-251, 2006. 